NASA Technical Memorandum 106965

\title{
The Effects of Ion Implantation on the Tribology of Perfluoropolyether-Lubricated 440C Stainless Steel Couples
}

Bradley Shogrin

Colorado State University

Fort Collins, Colorado

William R. Jones, Jr.

Lewis Research Center

Cleveland, Ohio

Paul J. Wilbur

Colorado State University

Fort Collins, Colorado

Pilar Herrera-Fierro

Ohio Aerospace Institute

Cleveland, Ohio

Don L. Williamson

Colorado School of Mines

Golden, Colorado

August 1995

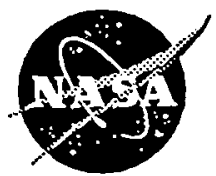

National Aeronautics and

Space Administration

Lenner con:

$40328 \mathrm{~K}^{\mathrm{N}}$

Li.:OIEY RESERTC:ICEITER

LoRARY its: 


\title{
THE EFFECTS OF ION IMPLANTATION ON THE TRIBOLOGY OF
}

\section{PERFLUOROPOLYETHER-LUBRICATED 440C STAINLESS STEEL COUPLES}

\author{
Bradley Shogrin \\ Department of Mechanical Engineering \\ Colorado State University \\ Fort Collins, Colorado 80523 \\ William R. Jones, Jr. \\ National Aeronautics and Space Administration \\ Lewis Research Center \\ Cleveland, Ohio 44135 \\ Paul J. Wilbur \\ Department of Mechanical Engineering \\ Colorado State University \\ Fort Collins, Colorado 80523 \\ Pilar Herrera-Fierro \\ Ohio Aerospace Institute \\ Cleveland, Ohio 44142 \\ and \\ Don L. Williamson \\ Physics Department \\ Colorado School of Mines \\ Golden, Colorado 80401
}

\begin{abstract}
The lubricating lifetime of thin films of a perfluoropolyether (PFPE) based on hexafluoropropene oxide in the presence of ion implanted $440 \mathrm{C}$ stainless steel is presented. Stainless steel discs, either unimplanted or implanted with $\mathrm{N}_{2}, \mathrm{C}, \mathrm{Ti}$, $\mathrm{Ti}+\mathrm{N}_{2}$, or, $\mathrm{Ti}+\mathrm{C}$ had a thin film of PFPE $(60-400 \AA)$ applied to them reproducibly $( \pm 20 \%)$ and uniformly $( \pm 15 \%)$ using a device developed for this study. The lifetimes of these films were quantified by measuring the number of sliding-wear cycles required to induce an increase in the friction coefficient from an initial value characteristic of the lubricated wear couple to a final, or failure value, characteristic of an unlubricated, unimplanted couple. The tests were performed in a dry nitrogen atmosphere $(<1 \% \mathrm{RH})$ at room temperature using a $3 \mathrm{~N}$ normal load with a relative sliding speed of $0.05 \mathrm{~ms}^{-1}$. The lubricated lifetime of the $440 \mathrm{C}$ couple was increased by an order of magnitude by implanting the disc with Ti. Ranked from most to least effective, the implanted species were: $\mathrm{Ti} ; \mathrm{Ti}+\mathrm{C}$; unimplanted $; \mathrm{N}_{2} ; \mathrm{C}=\mathrm{Ti}+\mathrm{N}_{2}$. The mechanism postulated to explain these results involves the formation of a passivating or reactive layer which inhibits or facilitates the production of active sites. The corresponding surface microstructures induced by ion implantation, obtained using x-ray diffraction and conversion electron Mössbauer spectroscopy, ranked from most to least effective in enhancing lubricant lifetime were: amorphous $\mathrm{Fe}-\mathrm{Cr}-\mathrm{Ti}$; amorphous $\mathrm{Fe}-\mathrm{Cr}-\mathrm{Ti}-\mathrm{C}+\mathrm{TiC}$; unimplanted; $\varepsilon-(\mathrm{Fe}, \mathrm{Cr})_{\mathrm{x}} \mathrm{N}, \mathrm{x}=2$ or 3 ; amorphous $\mathrm{Fe}-\mathrm{Cr}-\mathrm{C} \simeq$ amorphous Fe-Cr-Ti-N.
\end{abstract}




\section{INTRODUCTION}

Perfluoropolyethers (PFPEs) have been the liquid lubricants of choice for space applications for over twenty-five years because of their proven tribological performance and other attractive properties (1) such as low vapor pressure, low chemical reactivity, and the wide liquid temperature range. These oils are used in such space mechanisms as actuators, antenna pointing mechanisms, filter wheels, gyroscopes, and scanning mirrors $(2,3)$. In the past few years there have been several incidents during which PFPE-lubricated space mechanisms have shown anomalous behavior (4). These anomalies are thought to be the result of PFPE degradation.

A number of studies have focused on understanding and modeling the degradation of the PFPE lubricants. Research has repeatedly shown that PFPE's degrade while in boundary-lubricated, sliding/rolling contacts (5-10) and at elevated temperatures (11-14) losing their desirable properties, including lubricity. Although few models have been proposed to explain the observed degradation, it has been shown that the rate of degradation, under static, elevated temperature conditions, is dependent upon the surface chemistry of the substrate and relative strength of the Lewis acid substrates.

Kasai (11) has shown that the thermal catalytic degradation of a PFPE depends upon the strength of the Lewis acid substrate present, and has proposed a chemical degradation mechanism for each of the four commercial PFPE's. He postulated a mechanism in which a Lewis acid site acts as a catalyst that promotes an intramolecular disproportionation reaction that results in polymer-chain degradation.

Morales (14) concluded that the decomposition of a particular PFPE in the presence of various alumina microstructures at elevated temperatures could be attributed to chemically reducing sites on the alumina rather than Lewis acid sites. He demonstrated that silating the surface of the aluminas dramatically reduced the degradation rate.

Other degradation studies designed to explore the effects of certain metals or metal alloys in the presence of particular PFPEs have shown that PFPE degradation is highly dependent upon the chemistry of the substrate. For example, PFPE lubricants were shown to degrade at lower temperatures in the presence of $\mathrm{M}-50$ steel and Ti-4Al-4Mn than in contact with pure titanium or pure aluminum (13).

PFPE's have also been observed to break down chemically while in boundary lubricated contact with steels $(5,6,9,10)$. In each of these studies, the formation of the Lewis-acid solid $\mathrm{FeF}_{3}$ was observed on the wear track after the initiation of sliding. Compared to thermal degradation experiments, tribological experiments involve an extremely small amount of fluid with much smaller surface areas. Therefore, the tribological-induced chemical products are generated at a low rate which makes them difficult to detect. This has made it difficult to identify a detailed degradation mechanism. Although the degradation mechanism is not well understood, there are hypotheses. Carre (6) has proposed that the FeF ${ }_{3}$ Lewis acid solid is formed after the native oxide of the steel has been rubbed off and fresh, highly-reactive metal is exposed to the fluorinated oil. As sliding/ rolling persists, the Lewis acid continues to form and degrade the PFPE catalytically.

Mori and Morales (10) confirmed the catalytic process when they observed that contact between a $440 \mathrm{C}$ ball and disc caused $\mathrm{FeF}_{3}$ to form and induced the formation of degradation products. However, a recent study by Herrera-Fierro et al. (5) shows no measurable reaction takes place between an oxide-free $440 \mathrm{C}$ surface and a PFPE in vacuum at room temperature under static conditions. Reactions between the oxide-free surface and PFPE did occur at elevated temperatures $\left(190^{\circ} \mathrm{C}\right)$. Reactions were also observed when the oxide-free material was rubbed with a $440 \mathrm{C}$ ball, that yielded asperity temperatures estimated to be $<100^{\circ} \mathrm{C}$. In those two situations, similar decomposition by-products, including $\mathrm{FeF}_{3}$, were observed.

One way to inhibit tribo-induced degradation may be to utilize surfaces that do not promote the formation of Lewis acid solids in the presence of fluorinated oils. Carre (8) demonstrated that the PFPE-boundary-lubricated wear life was increased by a factor of 5 to 10 by using TiN coated $440 \mathrm{C}$ test specimens. TiC coated $440 \mathrm{C}$ and $\mathrm{Si}_{3} \mathrm{~N}_{4}$ ceramic ball bearings have also been shown to have greater longevity compared to their $440 \mathrm{C}$ counterparts when PFPE lubricated (7-9). In Carré's studies $(8,9)$ it was concluded that the hard coatings and ceramic material prevented the formation of Lewis acid solids, thus halting the Lewis-acid-induced degradation of the PFPE. 
The thesis of this work is that a $440 \mathrm{C}$ stainless steel surface can be implanted with ions that will passivate it, thereby inhibiting PFPE degradation and increasing the lubricant lifetime. A demonstration of the effect of ion implantation on the PFPE-lubricated lifetime of bearing material (440C) is sought rather than a detailed description of chemical degradation mechanisms.

Ion implantation is a surface-treatment technique that can be used to modify the surface properties of materials without affecting either the properties or dimensions of the bulk material beneath the treated layer. By introducing a foreign specie into a sub-micron surface layer, ion implantation can induce unique surface microstructures.

Since 1973 when the first work was done by Hartley et al. (15) on ion implanting substrates to benefit their tribological properties, extensive research in the area has shown that ion implantation can improve the materials wear $(16,17)$, friction $(17,18)$, and corrosion (19) properties. The main focus of these works has been on steels because of their wide use in tribological applications.

Therefore, the objective of this work was to study the effect of several ion implantation conditions on the lifetime of PFPE-lubricated $440 \mathrm{C}$ couples in sliding contact using a ball-on-disc apparatus. Carbon, nitrogen and titanium ions were investigated because these implanted species have shown to induce tribological improvements (15-19).

\section{EXPERIMENTAL}

\section{Materials}

Discs and bearing balls made from $440 \mathrm{C}$ stainless steel (fully hardened) were used. The $440 \mathrm{C}$ discs were $17.5 \mathrm{~mm}$ $\left(11 / 16^{\prime \prime}\right)$ in diameter and $4.76 \mathrm{~mm}\left(3 / 16^{\prime \prime}\right)$ thick. Each disc had a mirror finish with an arithmetic roughness average, $R_{a}$, of $\sim 0.01 \mu \mathrm{m}$. The bearing balls were Grade 10 with a diameter of $9.53 \pm 0.00102 \mathrm{~mm}(3 / 8 " \pm 0.00004 ")$.

A commercial perfluoropolyether (PFPE), based on hexafluoropropene oxide (HFPO), was applied as a thin, uniform film to discs prior to tribo-testing. The properties of this HFPO are given in Table 1. Bearing balls were not lubricated prior to testing.

\section{Ion Implantation and Sample Designation}

Discs that were implanted (no bearing balls were implanted) were first ultrasonically cleaned for approximately 10 minutes in each of the following solvents: trichloroethane, acetone, and methanol. Discs were implanted either using a metal-ion implanter (20) or a gaseous-ion implanter (21). The metal-ion implanter is designed to vaporize the metal by electron-bombardment heating. Both implanters utilize ion-propulsion technology and are designed to produce broad ion beams of high current densities (i.e. high dose rates).

The five implantation conditions used in this study and the number of discs implanted are given in Table 2. Eleven unimplanted discs were also tested. Three of the five implantation conditions involved titanium implantation either alone or with a backfill gas (nitrogen or methane). In the latter cases, the backfill-gas partial pressure was maintained at $2.7 \times 10^{-3} \mathrm{~Pa}$, giving a backfill-molecule arrival rate that was an order of magnitude greater than the ion arrival rate. This ensured adequate entrainment of the backfill gas into the layer along with the $\mathrm{Ti}$ which is a strong getter of both $\mathrm{N}$ and $\mathrm{C}$. The remaining two implantation conditions involved implantation of carbon (as $\mathrm{CH}_{4}$ ) or nitrogen.

Because wear testing of the implanted layers was conducted for short durations under sliding, low-Hertzian-pressure, boundary-lubricated conditions, the active tribological region on the disc was very thin $(<0.1 \mu \mathrm{m})$. Ion-implanted layers with thicknesses of this order can be produced using the energies indicated in Table 2 ( $50 \mathrm{or} 60 \mathrm{keV}$ ) at low temperature.

Consequently, implanted-ion temperature-induced diffusion was not required to enhance the layer thickness, allowing the 
substrate to remain at a low temperature $\left(<100^{\circ} \mathrm{C}\right)$ during implantation and assuring that no softening of the bulk material occurred.

The maximum benefit of a specie implanted at a given energy and a low temperature is expected at the saturation dose where the concentration profile in the layer becomes invariant with dose. For the energies and substrate temperatures used in this study the saturation dose of $2 \times 10^{17}$ ions $/ \mathrm{cm}^{2}(22,23)$ was used.

\section{Microstructure Characterization}

Each of the five implantation conditions was expected to induce different microstructures and compositions, and, therefore, different surface/lubricant chemistries. Implantation-induced microstructural and compositional changes were determined using backscattering conversion electron Mössbauer spectroscopy (CEMS) and X-ray diffraction (XRD).

The CEMS technique senses iron nearest-neighbor information in a surface layer with a thickness that is about equal to the implantation depth $(-0.1 \mu \mathrm{m})$. CEMS was used to determine the bonding of Fe atoms to each other and to other atoms and the relative concentration of these bonds. The bonding in turn determines the phases and microstructures that are present. CEMS was performed using ${ }^{57} \mathrm{Co}$ as the $\gamma$-ray source. $\mathrm{X}$-ray diffraction was performed using a $\mathrm{Cu} \mathrm{K}_{\alpha}$ source.

\section{Specimen Preparation}

Disc/ball pairs were ultrasonically cleaned in hexane, acetone, and finally methanol for approximately ten minutes each. The pair was then blown dry with nitrogen and promptly covered to minimize dust contamination. Following this, the pair was UV/ozone treated for 15 minutes to remove carbonaceous contamination (24). Discs that did not have PFPE applied to them, and all bearing balls were put into a dry $\mathrm{N}_{2}$ atmosphere within 5 minutes of the UV/ozone treatment where they stayed until tribo-tested. Discs that had PFPE applied to them were coated within 5 minutes of UV/ozone treatment and then placed in the same dry $\mathrm{N}_{2}$ environment and held at $\sim 25^{\circ} \mathrm{C}$.

\section{Application of Lubricant Films by Deposition from a Solution}

Thin-film deposition was accomplished by using the Film Deposition Device (FDD) shown in Fig. 1. This is a derivative of the deposition process known as dip-coating. In the dip-coating process, a specimen is coated by slowly withdrawing it at a constant speed from a solution of the fluid in a volatile solvent. As the solvent evaporates, a thin film of the nonvolatile fluid remains on the surface. In this procedure, both solution concentration and withdrawal speed govern the applied film thickness (25). For the apparatus used in this study, gravity-driven solution flowed past the stationary specimen. The surface speed that the solution attained as it flowed past the specimen, emptying from the bottom of the apparatus was approximately $0.8 \mathrm{~mm} / \mathrm{sec}$.

Nine of the unimplanted discs were coated using one of three concentrations of poly (HFPO) fluid $(1.0,3.0$, or $5.0 \mathrm{~g})$ in $100 \mathrm{ml}$ of perfluorinated cyclobutane (V-245). These discs were then tribo-tested to determine the effect of lubricant thickness on lubricant lifetime. It was determined that the thinnest lubricant film investigated yielded the most consistent wear test results in a reasonable time. Therefore, this HFPO film thickness (FDD mixture of $1.0 \mathrm{~g}$ in $100 \mathrm{ml}$ of solvent) was applied to the implanted discs.

\section{Lubricant Film Thickness Measurements}

The thickness of the poly (HFPO) fluid on each disc was measured using an infrared microscope ( $\mu$-FTIR) in the reflectance mode using a Grazing Angle Objective (GAO). A gold-coated glass slide was used as the background. 
Absorbance as a function of wave number was determined for each film at three different radii on the specimens' surface, approximately $120^{\circ}$ apart using an analysis spot diameter of $100 \mu \mathrm{m}$.

Theoretical thin film optical calculations were performed in order to model the HFPO film's behavior in the infrared (26). The results of this work, plotted as absorbance of the $1313 \mathrm{~cm}^{-1}$ band as a function of film thickness, is shown in Fig. 2. After experimentally obtaining the absorbance of the $1313 \mathrm{~cm}^{-1}$ band, the corresponding film thickness was obtained using Fig. 2.

The FDD apparatus produced PFPE film thicknesses of $60-80,230-280$, and $380-390 \AA$ corresponding to $1.0,3.0$, and $5.0 \mathrm{~g}$ in solution with $\mathrm{V}-245$, respectively. Lubricant uniformity across any one surface was $\pm 15 \%$. The error associated with surface-to-surface film thickness repeatability at each solution concentration was $\pm 20 \%$.

\section{Tribological Testing}

Tribological testing of each disc was performed on the fixed-ball-on-disc tribometer shown in Fig. 3. All tests were performed using a relative sliding speed of $0.05 \mathrm{~ms}^{-1}$ and a 3-N normal load which generated an initial Hertzian contact pressure of $\sim 0.69 \mathrm{GPa}$. All tests were run in dry $\mathrm{N}_{2}(<1 \% \mathrm{RH})$ at ambient temperatures $\left(-25^{\circ} \mathrm{C}\right)$. The frictional force as a function of disc revolutions (cycles) was recorded for each test (one wear track).

After a test, the ball support fixture and ball were rotated to expose an unworn surface on the ball and the fixture was extended so the ball would contact the disc at a different radius. By doing this, three virgin wear tracks, $1.59 \mathrm{~mm}\left(1 / 16^{\prime \prime}\right)$ apart, could be worn on each disc.

\section{RESULTS}

\section{Establishment of the Lubricant-Failure Criterion}

Lubricant failure was said to occur when the friction coefficient increased from an initial low value to a value typical of an unlubricated, unimplanted disc. When this occurred, we argue that the protective layer(s) (applied lubricant, surface oxide, and/or implanted layer) either wore off, ruptured, or broke down. Figure 4 shows the mean friction coefficient vs. cycle number of three wear tracks on two separate unlubricated discs. Mean friction coefficient is the mean of the friction coefficients of the complete revolution over the indicated cycle. Typically, friction-coefficient fluctuations over a cycle were \pm 0.06 (maximum: \pm 0.15 ) about the mean. The mean friction coefficient data all lie between 0.63 and 0.8 . Thus, an increase in mean friction coefficient above 0.63 was indicative of failure and 0.63 was defined as the failure limit. The numbers of rotational cycles that could be applied to the lubricant film on a wear track before the friction rose above the failure limit was the film's lubricating lifetime.

It was also important to know if the implantation processing itself changed the failure limit, therefore, one disc implanted with each specie was tested unlubricated. Initially, all the implanted surfaces exhibited lower mean friction coefficients $(\sim 0.3)$, but then rose linearly above the failure limit within 8 to 30 cycles on average. Table 3 summarizes these data. The average values appear outside the parentheses, whereas the ranges are contained within the parentheses. These data suggest that the uncertainty in lifetime is extended by no more than $\sim 30$ cycles as a result of implantation.

\section{Lubricant Thickness Results}

Unimplanted discs were coated with one of the three PFPE film thicknesses and tested. A typical plot of mean friction coefficient vs. cycle number is shown in Fig. 5. These particular data were taken from a disc with a $\sim 70 \AA$ PFPE film. The 
mean friction coefficient begins to rise from $\leq 0.3$ near 200 cycles and crosses the failure line of 0.63 at $\sim 370$ cycles (lubricant lifetime $=370$ cycles).

Although the lifetime from test to test varied substantially (discussed below), the history of each wear track was similar to the one depicted. In these tests the maximum variation of the friction coefficient before it began to rise (here at -200 cycles) was \pm 0.02 . This indicated that the entire wear track was uniformly experiencing the benefits of full boundary lubrication from the PFPE. After the initial rise, the variation of friction coefficient grew as the number of cycles increased until at the failure limit it typically had a variation of \pm 0.1 (maximum: \pm 0.20 , minimum: \pm 0.03 ). In the transition region, from a low to high mean friction coefficient, different locations on the wear track lose their lubricity at varying rates which accounts for the spread in friction coefficient seen over one cycle. Although the rate of lubricity loss over the entire wear track varied, and the variation increased as the number of cycles increased, the mean friction coefficient continued to rise, signifying an overall loss of lubricity. Beyond failure, variations of the friction coefficient over the rotational cycle, as well as the mean friction coefficient were sporadic. On some tracks the mean friction coefficient dipped below the failure line after it had reached failure (rarely dipping below -0.4 ). This decrease was caused by the rapidly growing wear scar coming into contact with fresh, unused PFPE lubricant. This fresh lubricant decreased the friction coefficient before it too degraded, causing the mean friction coefficient to again rise past the failure limit. These sporadic variations were also considered an indicator of failure.

After performing a number of the tests, it was apparent that the lifetimes had a significant spread in their values for each of the three PFPE thicknesses. These spreads in lifetime appeared random, as they did not depend upon either a particular disc or radius of wear track. Weibull analysis (27) was used to characterize these data.

The Weibull plots for the unimplanted discs coated with the three thicknessès of PFPE are shown in Fig. 6. Each data point represents the lubricated lifetime of one wear track. Each plot represents the fraction of a group of samples that can be expected to fail (i.e. exceed 0.63 friction coefficient) as a function of the number of sliding cycles. The straight lines drawn through the data represent the most probable failure history for the samples (i.e. the median-rank line). This suggests $1 \%$ of a given number of tests (B1 lifetime) of discs coated with $60-80 \AA$ of PFPE can be expected to undergo failure at or before $\sim 40$ cycles and $10 \%$ should fail at or before -130 cycles.

The slope of the median-rank line describes the repeatability of the data, with an infinite slope indicating all failures occur at the same number of cycles (100\% repeatability). The corresponding Weibull slope for the discs coated with $60-80 \AA$ of PFPE is 2.1 . Frequently, the characteristic life is cited. It is the number of cycles at the $63.2 \%$ failure condition (B63.2) and it is $\sim 380$ cycles for the discs coated with $60-80 \AA$ of PFPE.

Comparing all three Weibull plots, the shortest lifetimes belonged to the thinnest films and generally the longest to the thickest films, although lifetimes are similar for the thickest and intermediate thicknesses. The fact that the thicker films have about the same median-rank lines suggests that excess lubricant replenishes lubricant-depleted areas after the ball passes. However, this replenishment is not thought to occur by mass transport to-and-from the contact region as the ball passes which produces pileup adjacent to the wear scar. Here the lubricating films are too thin for this to happen. Rather, it is thought that the lubricant partakes in local, or nearest-asperity lubricant-replenishment, with the ball as the predominant driving force. The lack of mobility of these thin films may be the cause of the decrease in Weibull slope (2.1 to 1.6 to 1.2) that accompanies the increase in film thickness.

Because tests conducted with discs coated with $60-80 \AA$ PFPE films required less time to complete and also yielded the greatest repeatability, this thickness was selected as the standard in subsequent testing.

\section{Implanted - Lubricated Disc Tests}

Results obtained from implanted discs coated with a 60-80 A thick layer of PFPE were compared to results obtained on unimplanted discs. The history of a wear track from each implantation condition with a lubricated lifetime closest to its 
respective Weibull characteristic lifetime are compared to the history of an unimplanted disc in Fig. 7. Figure 7a shows complete histories to failure, whereas Fig. $7 \mathrm{~b}$ is an enlargement of the early failure-histories. The general characteristics of each condition were typical.

The friction coefficients for all of the discs are initially near 0.3 and for the cases shown, the shortest and longest lifetimes are $\sim 10$ cycles (carbon implanted) and $~ 3800$ cycles (titanium implanted), respectively, compared to $\sim 380$ cycles from the unimplanted one. The other three implantation conditions resulted in lifetimes between the two extremes $(\sim 80$ cycles for titanium+nitrogen, $\sim 220$ cycles for nitrogen and $\sim 1200$ for titanium+carbon).

Weibull plots comparing the lifetimes of the five sets of implanted discs to the unimplanted discs are shown in Fig. 8. Focusing on titanium implantation, it is apparent that titanium implantation of $440 \mathrm{C}$ discs induces almost an order of magnitude increase in the various lifetimes of the PFPE-lubricated surface. It also induces an increase in the Weibull slope from 2.1 for the unimplanted disc to 3.5 for the implanted one. The $99 \%$ reliability, or B1 life, for the titanium-implanted disc is $\sim 950$ cycles compared to $\sim 40$ cycles for the unimplanted one. The characteristic life of the disc was also increased from $\sim 380$ to $\sim 3560$ cycles by implanting it with $\mathrm{Ti}$.

These results show that titanium implantation with $\mathrm{CH}_{4}$ backfill also improves the lifetime, but all other implanted species reduce the lifetimes. The low Weibull slope induced by titanium implantation with nitrogen backfill $(\sim 0.6)$ suggests very poor repeatability, yields a B1 lifetime that is less than unity and is therefore unrealistic. The Weibull-plot.data are summarized in Table 4.

\section{Surface Microstructural and Compositional Data}

Differences in disc microstructures and compositions induced by ion implantation may suggest a mechanism by which lubricant lifetimes were altered. Therefore, XRD and CEMS measurements were made on one surface from each implantation condition. Figure 9a shows the XRD spectrum of each implanted surface. The $\mathrm{x}$-ray peaks were identified with the aid of the powder diffraction files (23). All show the strong peaks at $\sim 43^{\circ}$ and $\sim 65^{\circ}$ which are characteristic of a martensitic/ferritic phase. The peak at $\sim 51^{\circ}$ is indicative of an austenite phase, whose presence was confirmed by a resolved peak at $\sim 75^{\circ}$. The other peaks are characteristic of a metal carbide phase $\left(\mathrm{M}_{23} \mathrm{C}_{6}\right.$ where $\mathrm{M}=\mathrm{Fe}$ or $\left.\mathrm{Cr}\right)$.

The spectra of the titanium and titanium+nitrogen implanted surfaces are identical to the unimplanted surface's spectrum. This suggests that the $\mathrm{Ti}$ and $\mathrm{Ti}+\mathrm{N}_{2}$ implanted layers may either be too shallow to be detected by XRD or amorphous. The slight peak marked by the diamond on the spectrum of the titanium + carbon implanted surface is indicative of TiC. The asterisk-identified peaks (three of them) on the nitrogen implanted spectrum indicates an $\varepsilon-(\mathrm{Fe}, \mathrm{Cr})_{2+\mathrm{x}} \mathrm{N}$ phase. The broad, weak, unresolved peak at $\sim 43^{\circ}$ (indicated by cross-hatching) of the carbon implanted spectrum suggests an amorphous $\mathrm{Fe}-\mathrm{Cr}-\mathrm{C}$ phase.

Figure $9 \mathrm{~b}$ shows the CEMS spectrum for each surface. The spectrum of the unimplanted surface shows the dominant magnetic martensite/ferrite phase (designated $\mathrm{F}$ ) and the minor austenite + metal carbide phases (designated $\mathrm{A}+\mathrm{M}_{23} \mathrm{C}_{6}$, where $\mathrm{M}=\mathrm{Cr}$ mostly, and $\mathrm{Fe})(31,32)$. The CEMS spectra suggests that the $0.1-\mu \mathrm{m}$-thick surface layer on all of the implanted surfaces include a significant amount of the original martensitic/ferrite and austenitic/carbide phases. The titanium implanted surface contains, in addition, an amorphous $\mathrm{Fe}-\mathrm{Cr}$-Ti phase (28-30). The titanium+nitrogen, titanium+carbon and carbon implanted surfaces also contain slightly different amorphous phases (28-30). Because these phases are amorphous, XRD does not resolve them (except possibly the carbon implanted surface as noted previously). The TiC detected with XRD in the titanium+carbon implanted surface cannot be detected by CEMS because CEMS is only sensitive to Fe-containing compounds. It is probably because some $\mathrm{Ti}$ is consumed to form the $\mathrm{TiC}$ in this surface that the amount of amorphous phase in it is less than in the $\mathrm{Ti}$ and $\mathrm{Ti}+\mathrm{N}_{2}$ implanted discs (indicated by the lower amorphous-signal intensity). Finally, CEMS detected the presence of a hexagonal $\varepsilon-(\mathrm{Fe}, \mathrm{Cr})_{2+x} \mathrm{~N}$ like phase in the nitrogen implanted disc $(23,31)$. 
If one accepts the postulates that 1) longer lubricant lifetimes are realized when catalysts are deactivated, and 2) catalyst formation is inhibited via a passivating surface microstructure produced through ion implantation, then it is reasonable to correlate surface microstructures and lifetimes. This suggests the microstructures ranked from most to least effective are:

amorphous $\mathrm{Fe}-\mathrm{Cr}-\mathrm{Ti}>$ amorphous $\mathrm{Fe}-\mathrm{Cr}-\mathrm{Ti}-\mathrm{C}+\mathrm{TiC}>$ unimplanted $440 \mathrm{C} \geq \varepsilon-(\mathrm{Fe}, \mathrm{Cr})_{\mathrm{x}} \mathrm{N}[\mathrm{x}=2$ or 3] $>$ amorphous $\mathrm{Fe}-\mathrm{Cr}-\mathrm{Ti}-\mathrm{N}$ $\simeq$ amorphous $\mathrm{Fe}-\mathrm{Cr}-\mathrm{C}$.

\section{DISCUSSION}

The data of Figs. 7 and 8 and Table 3 indicate that the lubricating lifetime of PFPE on a 440C disc sliding against a 440C ball can be altered significantly by implanting a disc with various ions. The reason for these changes is uncertain, but it is known that implantation can induce both chemical and microstructural changes in materials. It is also known that PFPE oils can degrade as a result of chemical reaction with a surface and that the rate of the degradation is a strong function of temperature. In addition, implantation may alter the way in which the PFPE molecules attach to the disc and that this, in turn, changes the shear stress they experience and, therefore, the likelihood that they will be torn apart mechanically. Hence, it is suggested that ion implantation can alter the lifetime of a PFPE film by changing the rate of 1) mechanical scission of the molecular chains and/or 2) chemical degradation in the thermal environment of tribo-contact. The following discussion addresses the likelihood that these mechanisms are significant.

\section{Mechanical Scission}

It has been observed that the shear stress at a boundary lubricated tribological contact can result in the fracture of lubricant bonds (mechanical scission) (33). In the present case, the value of shear stress can be estimated knowing the frictional force and Hertzian contact area. Since the applied normal load is the same for all tests and the implanted layers are so thin they should not affect the contact area significantly, one expects the shear stress to be directly proportional to the friction coefficient. Because the friction coefficient varied over the same ranges for all tests, it is argued that mechanical scission effects were the same for all discs. This, in turn, suggests that mechanical scission was probably not a significant contributor to differences in tribological lifetime induced by ion implantation.

\section{Chemical Degradation}

It has been established that a PFPE-lubricated $440 \mathrm{C}$ couple in boundary contact will eventually result in the formation of the Lewis acid $\mathrm{FeF}_{3}(5,6,9,10)$. This acid formation is thought to lead to PFPE degradation. It has been observed that the more readily the Lewis acids form and the stronger they are, the quicker the PFPE degrades. Therefore, a passivating layer that inhibits Lewis acid formation would be expected to increase the effective lifetime of the lubricant.

It has been shown that the rate of Lewis acid formation is greatly affected by temperature. Therefore, it is feasible that a high temperature rise at the asperity contacts could induce PFPE breakdown. This concept has received mixed reviews. For example, Carré attributes PFPE degradation in sliding/rolling contact to high asperity temperatures $(6,8)$. However, Mori et al. (10) discarded this as the cause, and Herrera-Fierro et al. (5) suggested their asperity temperatures were not high enough to induce degradation.

In an attempt to determine their impact, bulk and flash temperatures were calculated using a computer program entitled "T-Maps" written by Ashby et al. $(34,35)$ that theoretically calculates contact temperatures in dry sliding contact. Inputs to this program include: geometry (ball on flat), thermal and mechanical material properties, radius of the area of contact, Hertzian stress, sliding speed, friction coefficient $(0.63)$, ambient temperature $\left(25^{\circ} \mathrm{C}\right)$ and asperity radius. An asperity radius $\left(R_{\mathrm{a}}\right)$ of $13 \mu \mathrm{m}$ was obtained from the expression $\left(\mathrm{R}_{\mathrm{a}}=0.1 / \mathrm{H}\right)$ given by Ashby $(35)$ which requires the hardness $(\mathrm{H})$ of $440 \mathrm{C}$ steel ( $7500 \mathrm{MPa}$ ). The bulk and asperity temperatures were calculated to be $\sim 50^{\circ} \mathrm{C}$ and $\sim 70^{\circ} \mathrm{C}$, respectively. 
Since implantation generally hardens a surface, (16) and the asperity radius decreases with hardness, it is logical to expect implantation to cause asperity temperatures to increase. However, the Ashby-model shows that reducing the asperity radius by half the value used above, which corresponds to doubling the hardness, induced only a $\sim 15 \%$ increase in the bulk and asperity temperatures. Even these temperatures, which are conservatively high because the effects of the lubricant are neglected, are well below the $200-300^{\circ} \mathrm{C}$ needed to induce rapid PFPE degradation on $440 \mathrm{C}$ steel (5). Hence, these results suggest that temperatures at the contact are not sufficiently high enough to induce significant PFPE breakdown.

\section{CONCLUSIONS}

1. Thin films of PFPE lubricant $(60-400 \AA)$ were applied to flat metal discs, reproducibly $( \pm 20 \%)$ and uniformly $( \pm 15 \%)$ using a film deposition device.

2. Ion implantation of $440 \mathrm{C}$ steel discs with $\mathrm{Ti}, \mathrm{Ti}+\mathrm{N}_{2}, \mathrm{Ti}+\mathrm{C}, \mathrm{N}_{2}$, or $\mathrm{C}$ all cause the number of unlubricated sliding-wear-cycles-to-failure to increase from near zero for the unimplanted $440 \mathrm{C}$ couple to about 10 cycles.

3. The B63.2 (characteristic life) and B1 lifetimes of the $440 \mathrm{C}$ couple were increased by an order of magnitude and a factor of 24, respectively, by implanting with Ti. Implantation with $\mathrm{Ti}+\mathrm{C}$ also induced improvements in these lifetimes, but implantation with $\mathrm{Ti}+\mathrm{N}_{2}, \mathrm{~N}_{2}$ and $\mathrm{C}$ did not.

4. The surface microstructures produced by the implantation ranked from most to least effective in enhancing lubricant lifetime are:

amorphous Fe-Cr-Ti ; amorphous Fe-Cr-Ti-C + TiC ; unimplanted $440 \mathrm{C} ; \varepsilon-(\mathrm{Fe}, \mathrm{Cr})_{x} \mathrm{~N}, \mathrm{x}=2$ or 3 ; amorphous $\mathrm{Fe}-\mathrm{Cr}-\mathrm{C}=$ amorphous Fe-Cr-Ti-N.

5. Ranked from most to least effective, the implanted species were: $\mathrm{Ti} ; \mathrm{Ti}+\mathrm{C}$; unimplanted $; \mathrm{N}_{2} ; \mathrm{C} \simeq \mathrm{Ti}+\mathrm{N}_{2}$.

\section{REFERENCES}

1. Jones, W.R., Jr.: “The Properties of Perfluoropolyethers Used for Space Applications," NASA TM-106275, (July 1993).

2. Fleischauer, P.D., and Hilton, M.R.: "Assessment of the Tribological Requirements of Advanced Spacecraft Mechanisms," Aerospace Corp., TOR-0090(5064)-1, (1991).

3. Rowntree, R.A., and Todd, M.J.: "A Review of European Trends in Space Tribology and Its Application to Spacecraft Mechanism Design," Mat. Res. Soc. Symp. Proc., 140, 21-34, (1989).

4. Watson, N.D., Miller, J.B., Taylor, L.V., Lovell, J.B., Cox, L.W., Fedors, J.C., Kopia, L.P., Holloway, R.M., and Bradley, O.H.: "Earth Radiation Budget Experiment (ERBE) Scanner Instrument Anomaly Investigation," NASA TM-87636, (Oct. 1985).

5. Herrera-Fierro, P., Jones, W.R., Jr., and Pepper, S.V.: "Interfacial Chemistry of a Perfluoropolyether Lubricant Studied by X-ray Photoelectron Spectroscopy and Temperature Desorption Spectroscopy," J. Vac. Sci. Technol. A, 2 (11), 354-367, (Mar/Apr 1993).

6. Carré, D.J.: "Perfluoropolyalkylether Oil Degradation: Inference of $\mathrm{FeF}_{3}$ Formation on Steel Surfaces Under Boundary Conditions," ASLE Trans., 29 (2), 121-125, (1986).

7. Hayashida, K., Yamamoto, K., and Nishimura, M.: "Wear and Degradation Characteristics of Perfluoroalkylpolyethers (PFPEs) in High Vacuum," Trib. Trans. 37 (1), 196-200, 1994.

8. Carré, D.J.: "The Use of Solid Ceramic and Ceramic Hard-Coated Components to Prolong the Performance of Perfluoropolyalkylether Lubricants," Surface and Coatings Tech., 43/44, 606-617, (1990).

9. Carré, D.J.: "The Performance of Perfluoropolyalkyethers Under Boundary Conditions," Trib. Trans., 31 (4), (1988).

10. Mori, S., and Morales, W.: "Tribological Reactions of Perfluoroalkylpolyether Oils with Stainless Steel Under Ultrahigh Vacuum Conditions at Room Temperature," Wear, 132, 111-121, (1989).

11. Kasai, P.H.: "Perfluoropolyethers: Intramolecular Disproportionation,"Macromolecules, 25, 6791-6799, (1992).

12. Carré, D.J., and Markowitz, J.A.: "The Reaction of Perfluoropolyalkylether Oil with $\mathrm{FeF}_{3}, \mathrm{AlF}_{3}$, and $\mathrm{AlCl}_{3}$ at Elevated Temperatures," ASLE Trans., 28 (1), 40-46, (1985). 
13. Jones, W.R., Jr., Paciorek, K.J.L., Harris, D.H., Smythe, M.E., Nakahara, J.H., and Kratzer, R.H.: "The Effects of Metals and Inhibitors on Thermal Oxidative Degradation Reactions of Unbranched Perfluoroalkyl Ethers," R. H. Ind. Eng. Chem. Prod. Res. Dev., 24, 417-420, (Sept 1985).

14. Morales, W.: "Perfluoropolyalkylether Decomposition on Catalytic Aluminas," NASA TM-106547, (Apr 1994).

15. Hartley, N.E.W., Swindlehurst, W.E., Dearnaley, G., and Turner, J.F.: "Friction Changes in Ion-Implanted Steel," J. of Materials Sci., 8, 900-904, (1973).

16. Wei, R., Shogrin, B., Wilbur, P.J., Ozturk, O., Williamson, D.L., Ivanov, I., and Metin, E.: “The Effects of Low-Energy-Nitrogen-Ion-Implantation on the Tribological and Microstructural Characteristics of AISI 304 Stainless Steel," J. of Tribology, 116 (4), 870-876, (Oct 1994).

17. Pope, L.E., Yost, F.G., Follstaedt, D.M., Picraux, S.T. and Knapp, J.A.: "Friction and Wear Reduction of $440 C$ Stainless Steel By Ion Implantation," Mat. Res. Soc. Symp. Proc., 27, 661-666, (1984).

18. Singer, I.L., and Jeffries, R.A.: "Effects of Implantation Energy and Carbon Concentration on the Friction and Wear of Titanium-Implanted Steel," Appl. Physics Letters, 43 (10), 925-927, (Nov 1983).

19. Misra, M.S., and Kustus, F.M., Edited by Clayton, C.R., and Preece, C.M.: "Corrosion Resistance of Ion Implanted 303 Stainless Steel, 52100 Bearing Steel, and 2024-T3 Aluminum Alloy," Corrosion of Metals Processed by Directed Energy Beams, (1981).

20. Wilbur, P.J., and Wei, R.: "High Current-Density Metal-Ion Implantation," Rev. Sci. Instrum., 63 (4), 2491-2493, (Apr 1992).

21. Wilbur, P.J. and Daniels, L.O.: "The Development and Application of an Ion Implanter Based on Ion Thruster Technology," Vacuum, 36, 5-9, (1986).

22. Singer, I.L., and Jeffries, R.A.: "Processing Steels for Tribological Applications by Titanium Implantation," ASLE Trans., 28 (1), 134-138, (1984).

23. Z Powder Diffraction Files, International Centre for Diffraction Data, 12 Campus Blvd., Newtown Square, PA 19073-3273.

24. Vig, J.R.: "UV/Ozone Cleaning of Surfaces," J. Vac. Sci. Technol. A, 3 (3), 1027-1034, (May/Jun 1985).

25. Scarati, A.M., and Caporiccio, G.: "Frictional Behaviour and Wear Resistance of Rigid Disks Lubricated with Neutral and Functional Perfluoropolyethers," IEEE Trans. on Magnetics, 23 (1), 106-108, (Jan 1987).

26. Pepper, S.V.: "Characterization and Application of a Grazing Angle Objective for Quantitative Infrared Reflection Spectroscopy," Appl. Spect., 49 (3), 354-360, (Mar 1995).

27. Johnson, L.G.: The Statistical Treatment of Fatigue Exper., Elsevier Publishing Company, Inc., (1964).

28. Williamson, D.L., Singer, I.L., Wei, R., and Wilbur, P.J.: "Amorphous Fe-Ti-C Phase Produced by Ion Implantation of Iron and Its Role in Tribological Behavior," Nuclear Instruments and Methods in Phys. Res., B76, 210-212, (1993).

29. Williamson, D.L., Kustas, F.M., Fobare, D.F., and Misra, M.S.: "Mössbauer Study of Ti-Implanted 52100 Steel," Appl. Phys., 60 (4), 1493-1500, (1986).

30. Williamson, D.L., Kustas, F.M., Qu, Yi, and Smith, S.R.: "Titanium and Carbon Implantation of Iron," Hyperne Interactions, 42, 1029-1032, (1988).

31. Kustas, F.M., Misra, M.S., and Williamson, D.L.: "Microstructural Characterization of Nitrogen Implaned 440C

Steel," Nuclear Instruments and Methods in Phys. Res., B31, 393-401, (1988).

32. Vardavoulias, M. and Papadimitriou, G.: Mössbauer Spectra and Hyperfine Parameters of Iron-Chromium Carbides in Ferritic Stainless Steel," Phys. Stat. Sol., 134, 183-191, (1992).

33. Karis, T.E., Novotny, V.J., and Johnson, R.D.: "Mechanical Scission of Perfluoropolyethers," J. of Appl. Polymer Sci., 50, 1357-1368, (1993).

34. Ashby, M.F., Abulawi, J., and Kong, H.S.: “Temperature Maps for Frictional Heating in Dry Sliding," Tribology Trans., 34 (4), 577-587, (1991).

35. Ashby, M.F., Kong, H.S., and Abulawi, J.: "Operation Manual for T-Maps, A Program for Constructing Maps for Surface Heating in Unlubricated Sliding," Ver. 2.0, Engineering Dept., Cambridge, U.K., (Jun 1990). 
Table 1.-Selected Properties of the PFPE Used in the Study

\begin{tabular}{|c|c|}
\hline Average molecular weight & $11000 \mathrm{amu}$ \\
\hline $\begin{array}{r}\text { Vapor pressure at } 20^{\circ} \mathrm{C} \\
\text { at } 50^{\circ} \mathrm{C} \\
\text { at } 100^{\circ} \mathrm{C}\end{array}$ & $\begin{array}{l}4 \times 10^{-12} \mathrm{~Pa} \\
3 \times 10^{-10} \mathrm{~Pa} \\
1 \times 10^{-7} \mathrm{~Pa}\end{array}$ \\
\hline $\begin{array}{r}\text { Kinematic viscosity at } 20^{\circ} \mathrm{C} \\
\text { at } 50^{\circ} \mathrm{C} \\
\text { at } 100^{\circ} \mathrm{C}\end{array}$ & $\begin{array}{r}2717 \mathrm{~mm}^{2} \mathrm{~s}^{-1} \\
444 \mathrm{~mm}^{2} \mathrm{~s}^{-1} \\
63 \mathrm{~mm}^{2} \mathrm{~s}^{-1}\end{array}$ \\
\hline $\begin{array}{r}\text { Density at } 20^{\circ} \mathrm{C} \\
\text { at } 50^{\circ} \mathrm{C} \\
\text { at } 100^{\circ} \mathrm{C}\end{array}$ & $\begin{array}{l}1.92 \mathrm{gcm}^{-3} \\
1.87 \mathrm{gcm}^{-3} \\
1.78 \mathrm{gcm}^{-3}\end{array}$ \\
\hline Surface tension at $25^{\circ} \mathrm{C}$ & 19 dynescm$^{-1}$ \\
\hline
\end{tabular}

Table 2.-Implantation Conditions Used in the Study

\begin{tabular}{|l|c|c|c|c|c|}
\hline $\begin{array}{c}\text { Implanted } \\
\text { specie }\end{array}$ & Backfill & $\begin{array}{c}\text { Energy, } \\
\mathrm{keV}\end{array}$ & $\begin{array}{c}\text { Dose rate, } \\
\mu \mathrm{A} / \mathrm{cm}^{2}\end{array}$ & $\begin{array}{c}\text { Dose, } \\
\text { ions } / \mathrm{cm}^{2}\end{array}$ & Number of discs \\
\hline $\mathrm{Ti}$ & None & 50 & 200 & $2.0 \times 10^{17}$ & 4 \\
\hline $\mathrm{Ti}$ & $\mathrm{N}_{2}$ & 50 & 200 & $2.0 \times 10^{17}$ & 3 \\
\hline $\mathrm{Ti}$ & $\mathrm{CH}_{4}$ & 50 & 200 & $2.0 \times 10^{17}$ & 4 \\
\hline $\mathrm{N}_{2}$ & None & 60 & 100 & $1.0 \times 10^{17}$ & 4 \\
\hline $\mathrm{CH}_{4}$ & None & 60 & 100 & $2.0 \times 10^{17}$ & 3 \\
\hline
\end{tabular}


Table 3.-Unlubricated Wear Test Results

\begin{tabular}{|l|c|c|c|}
\hline \multicolumn{1}{|c|}{ Surface treatment } & $\begin{array}{c}\text { Initial mean friction } \\
\text { coefficient }\end{array}$ & $\begin{array}{c}\text { Number of cycles } \\
\text { until failure }\end{array}$ & $\begin{array}{c}\text { Tracks } \\
\text { tested }\end{array}$ \\
\hline Ti Implanted-No Backfill & $0.32(0.27-0.36)$ & $12(11-13)$ & 4 \\
\hline Ti Implanted-N, Backfill & $0.29(0.27-0.32)$ & $8(7-10)$ & 3 \\
\hline Ti Implanted- $\mathrm{CH}_{4}$ Backfill & $0.28(0.27-0.29)$ & $11(10-12)$ & 2 \\
\hline $\mathrm{N}_{2}$ Implanted & $0.34(0.32-0.36)$ & $30(11-58)$ & 4 \\
\hline $\mathrm{C}$ Implanted & $0.27(0.24-0.29)$ & $8(7-9)$ & 4 \\
\hline
\end{tabular}

Table 4.-Summary of Data Obtained from Weibull Plots

\begin{tabular}{|l|c|c|c|}
\hline Surface treatment & $\begin{array}{l}\text { B1 Life, } \\
\text { cycles }\end{array}$ & $\begin{array}{c}\text { Characteristic life, } \\
\text { cycles }\end{array}$ & Weibull slope \\
\hline Unimplanted & 40 & 380 & 2.1 \\
\hline Ti Implanted & 950 & 3560 & 3.5 \\
\hline $\begin{array}{l}\text { Ti Implanted } \\
\mathrm{N}_{2} \text { Backfill }\end{array}$ & $\ldots$ & 190 & 0.6 \\
\hline $\begin{array}{l}\text { Ti Implanted } \\
\mathrm{CH}_{4} \text { Backfill }\end{array}$ & 400 & 1090 & 4.6 \\
\hline $\mathrm{N}_{2}$ Implanted & 10 & 210 & 1.6 \\
\hline $\mathrm{C}_{\text {Implanted }}$ & $<10$ & 20 & 4.2 \\
\hline
\end{tabular}




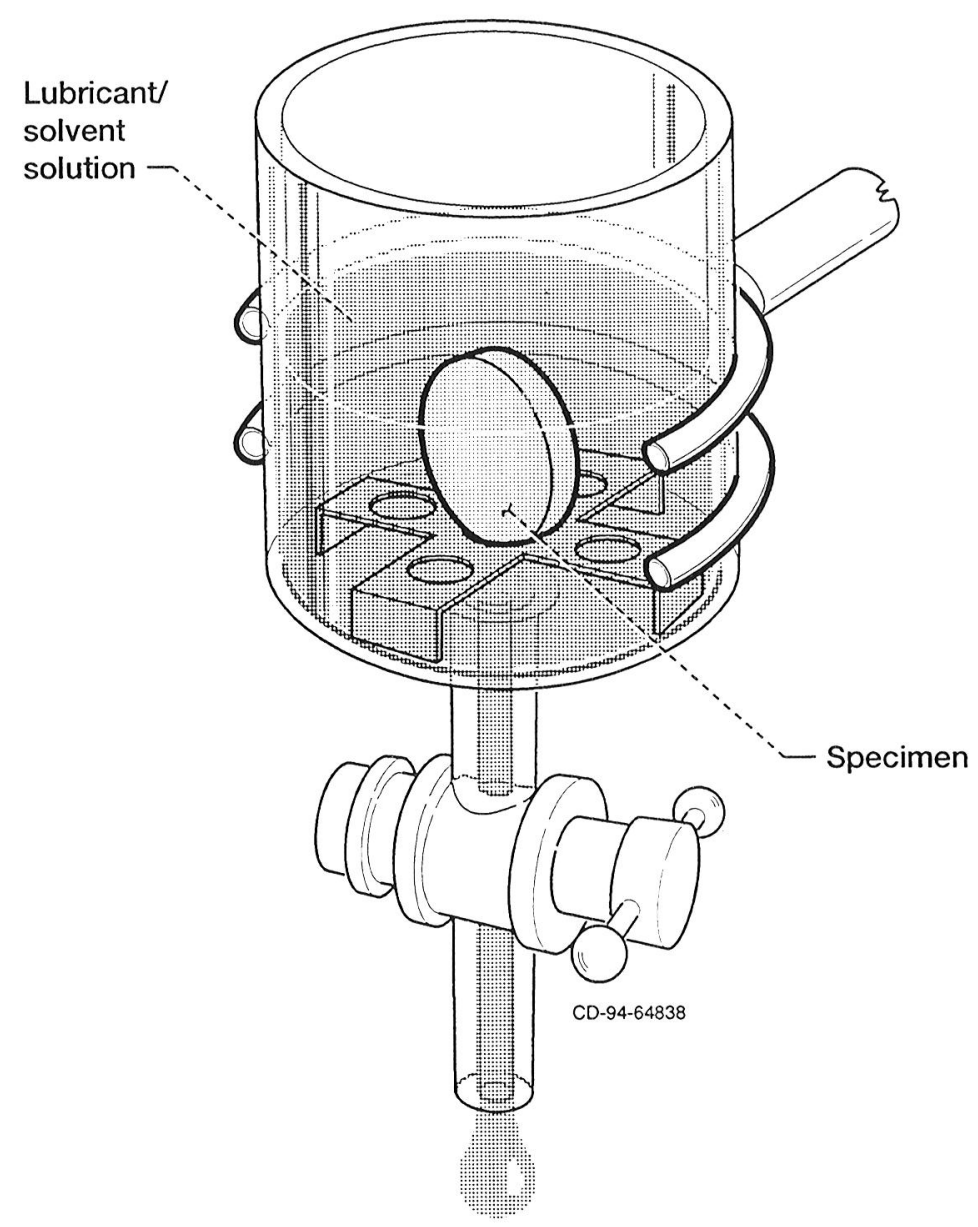

Figure 1.-Film deposition device (FDD). 


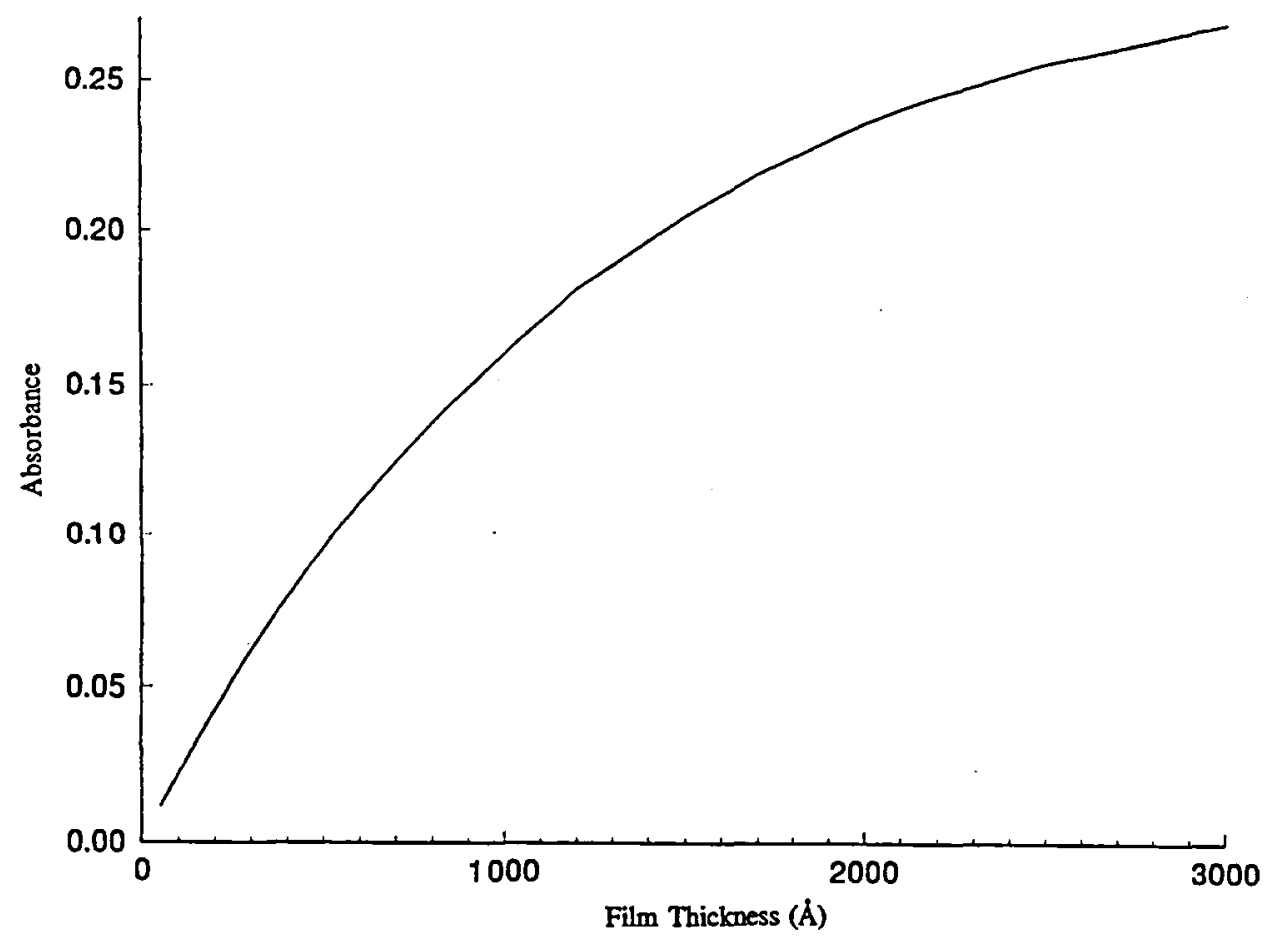

Figure 2. Calculated IR absorbances for the $1313 \mathrm{~cm}^{-1}$ band of HFPO as a function of film thickness.

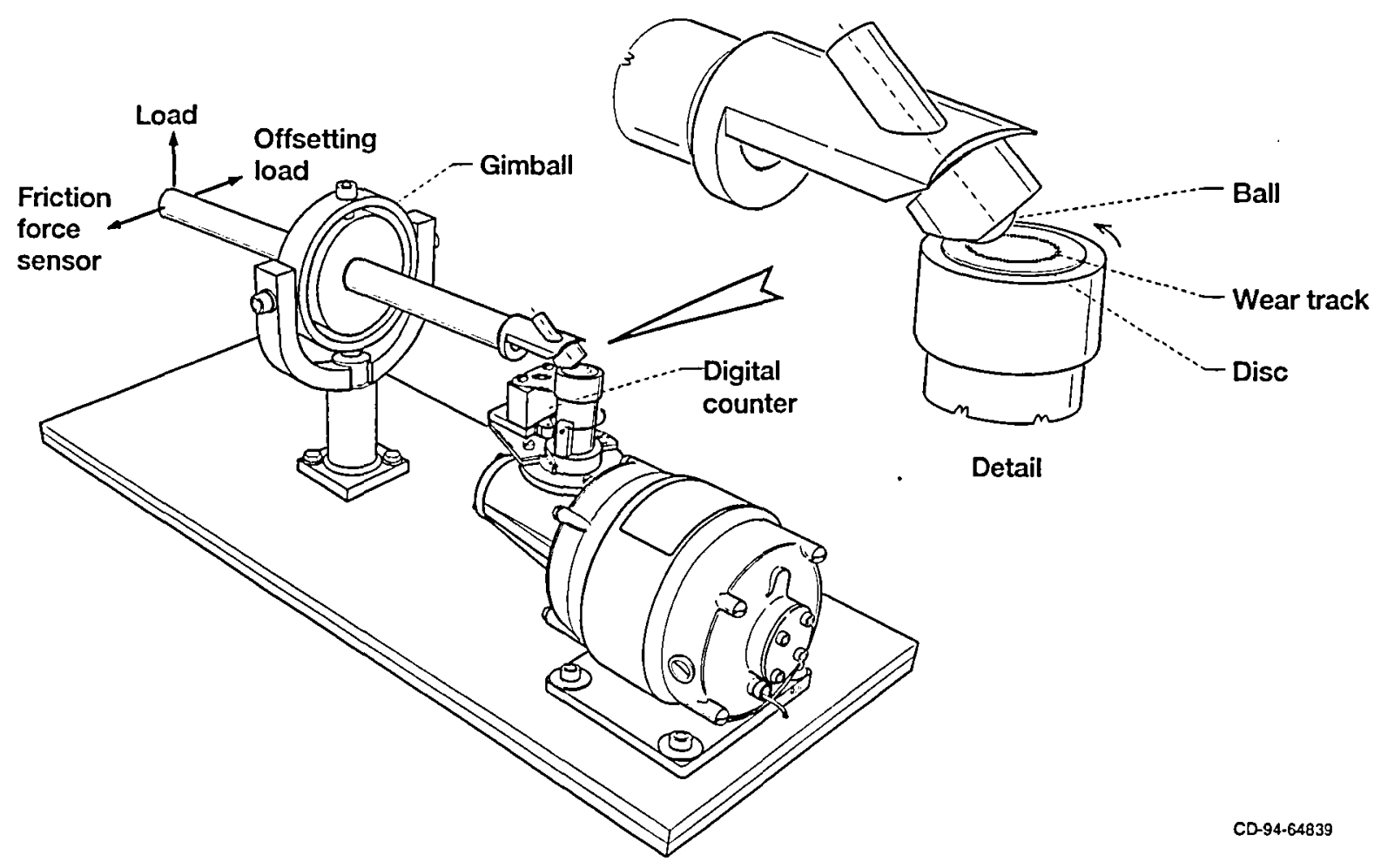

Figure 3.-Ball-on-disk tribometer. 


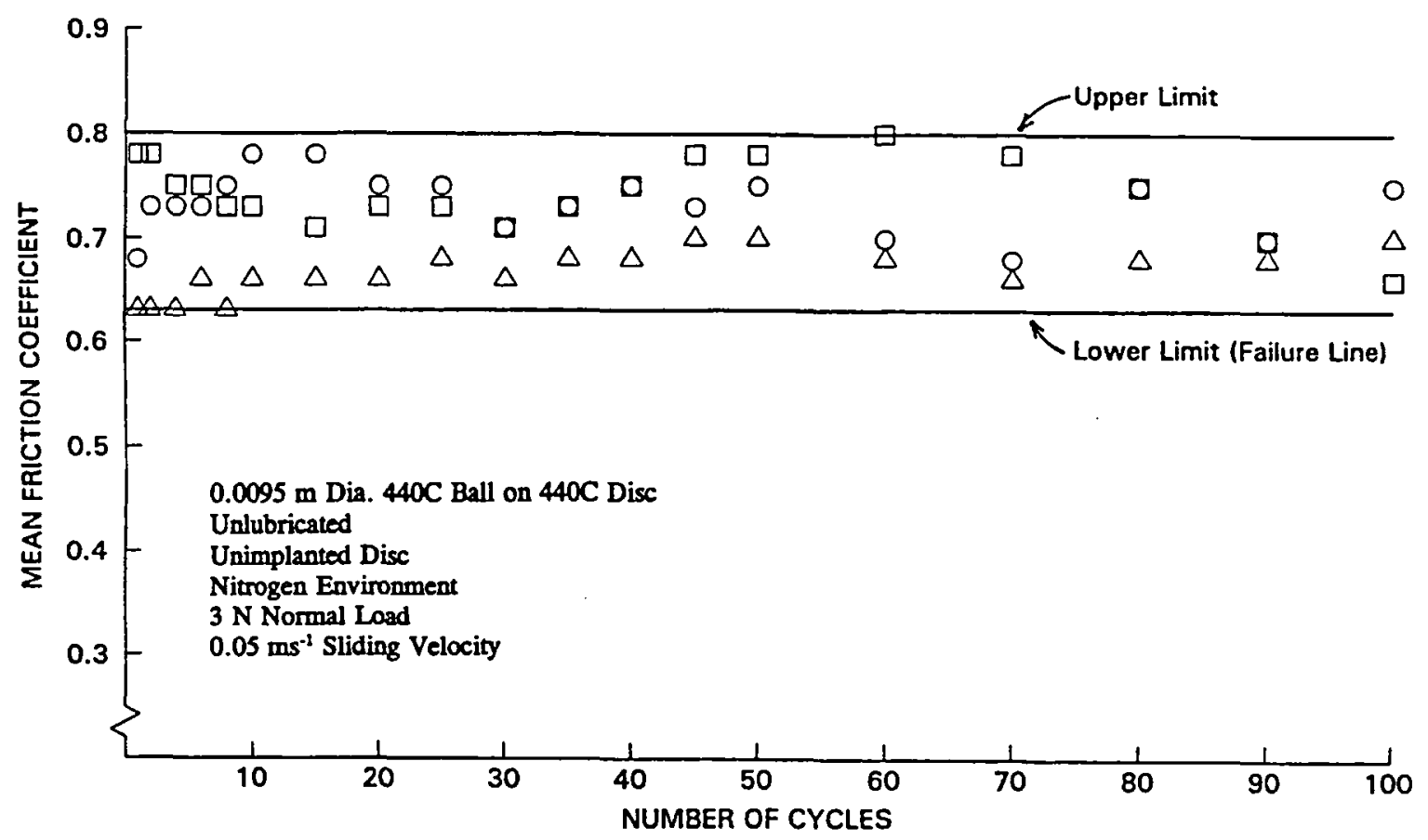

Figure 4. Typical Friction Coefficient Data for Unimplanted, Unlubricated Discs.

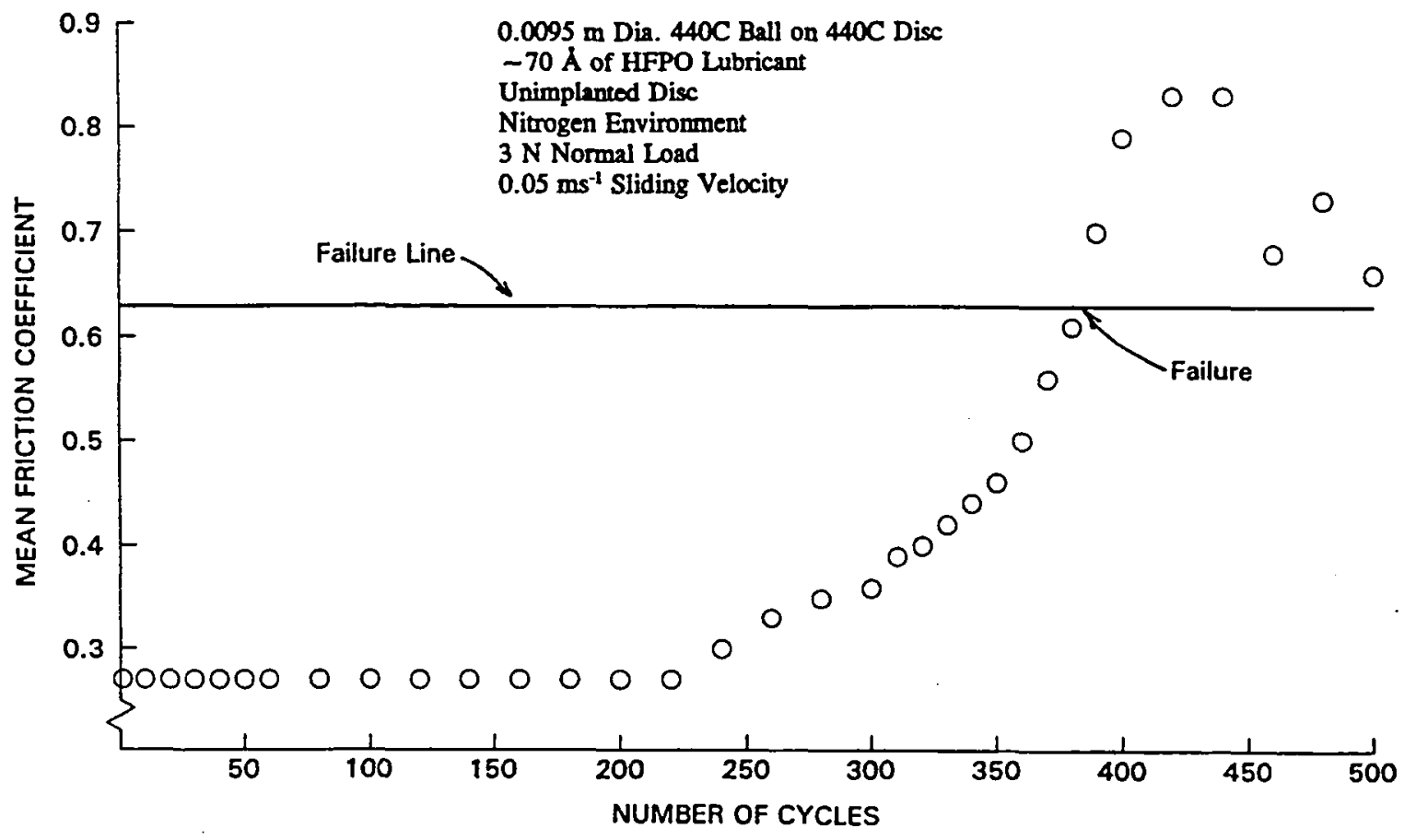

Figure 5. Typical Friction Coefficient Data for Unimplanted, Lubricated Discs. 


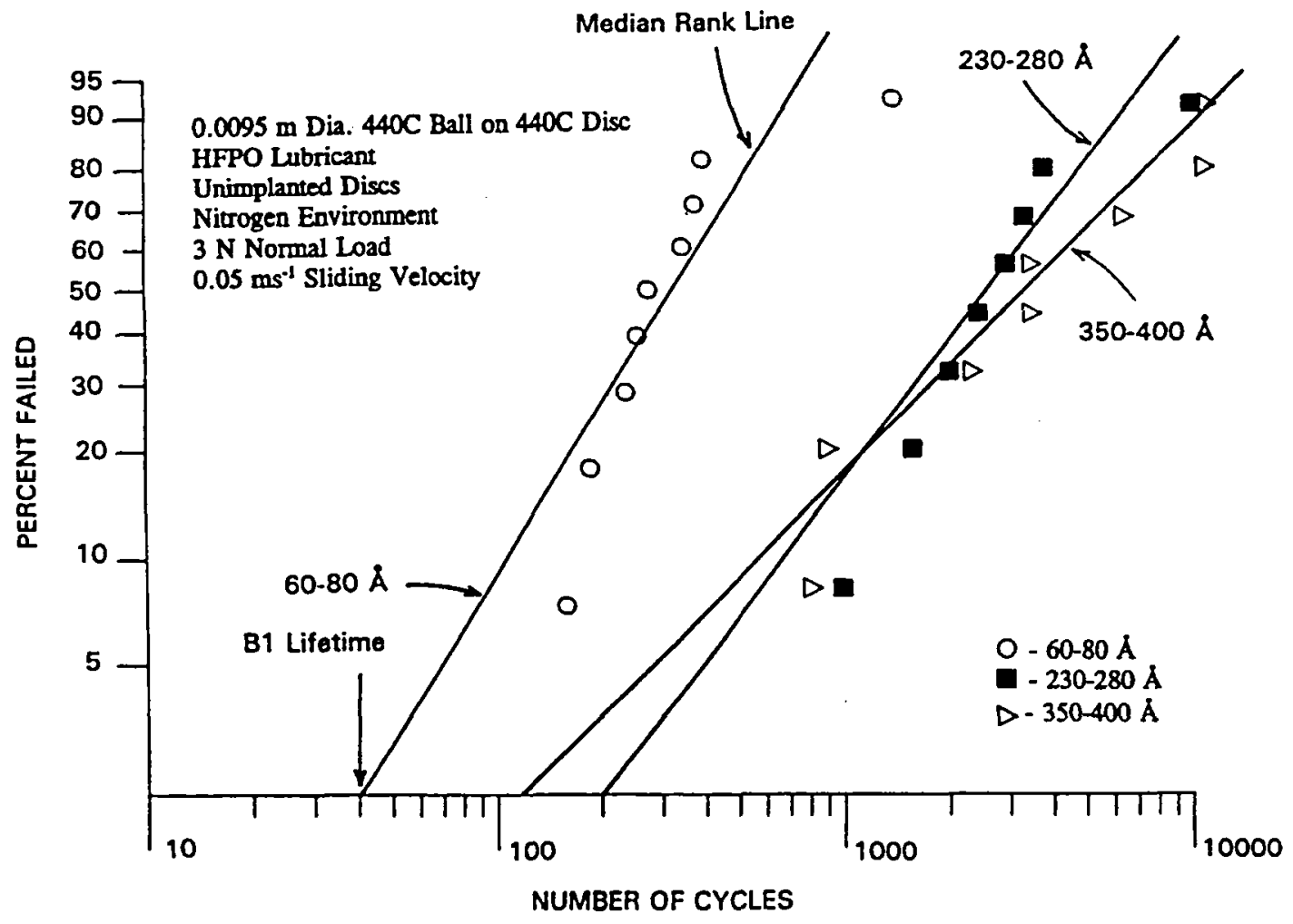

Figure 6. Effect of Lubricant Thiciness on Weibull Distribution Lifetimes for Unimplanted Discs. 


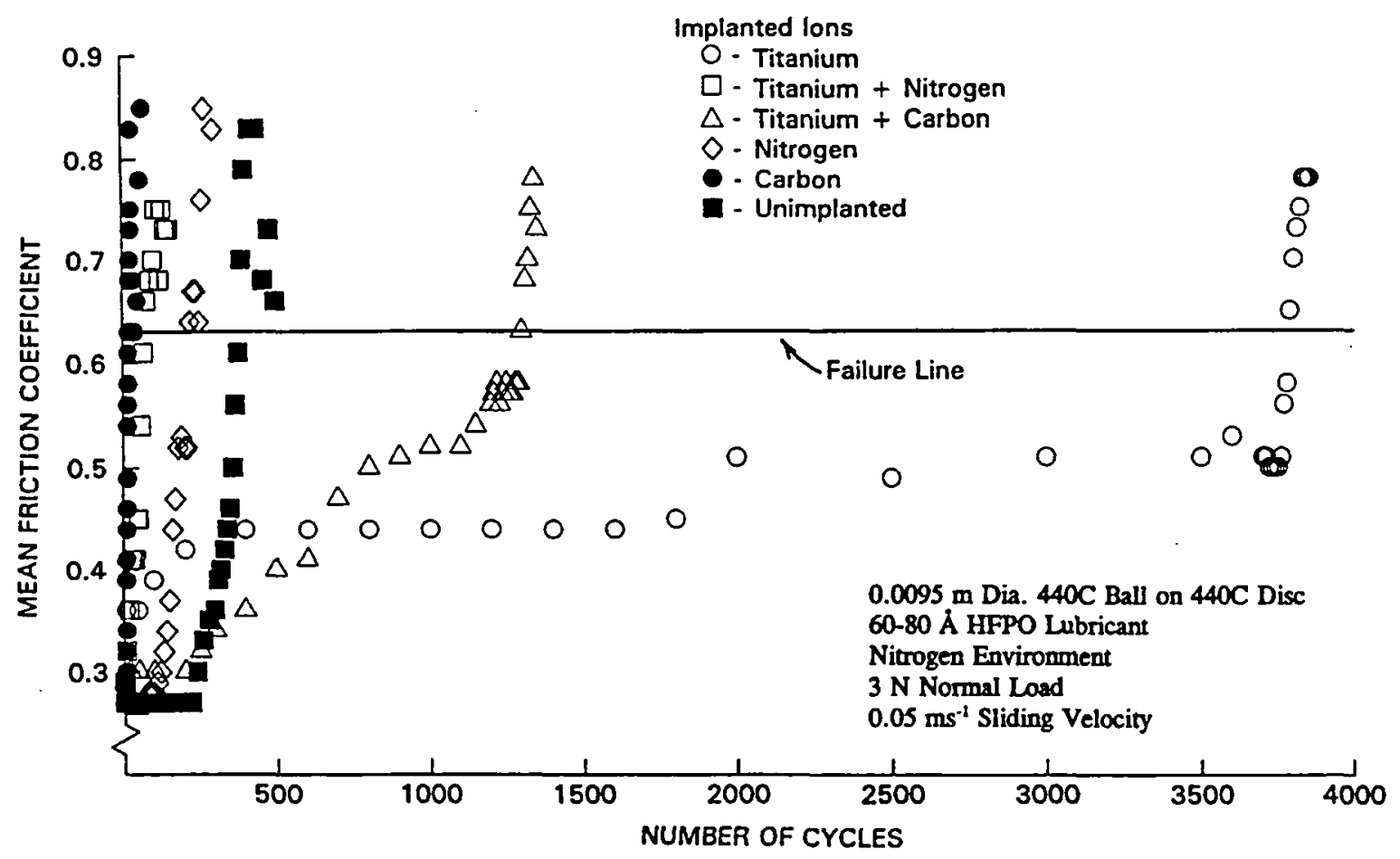

Figure 7. Typical Friction History Showing Effect of Ion Implantation Part a. Complete History to Failure

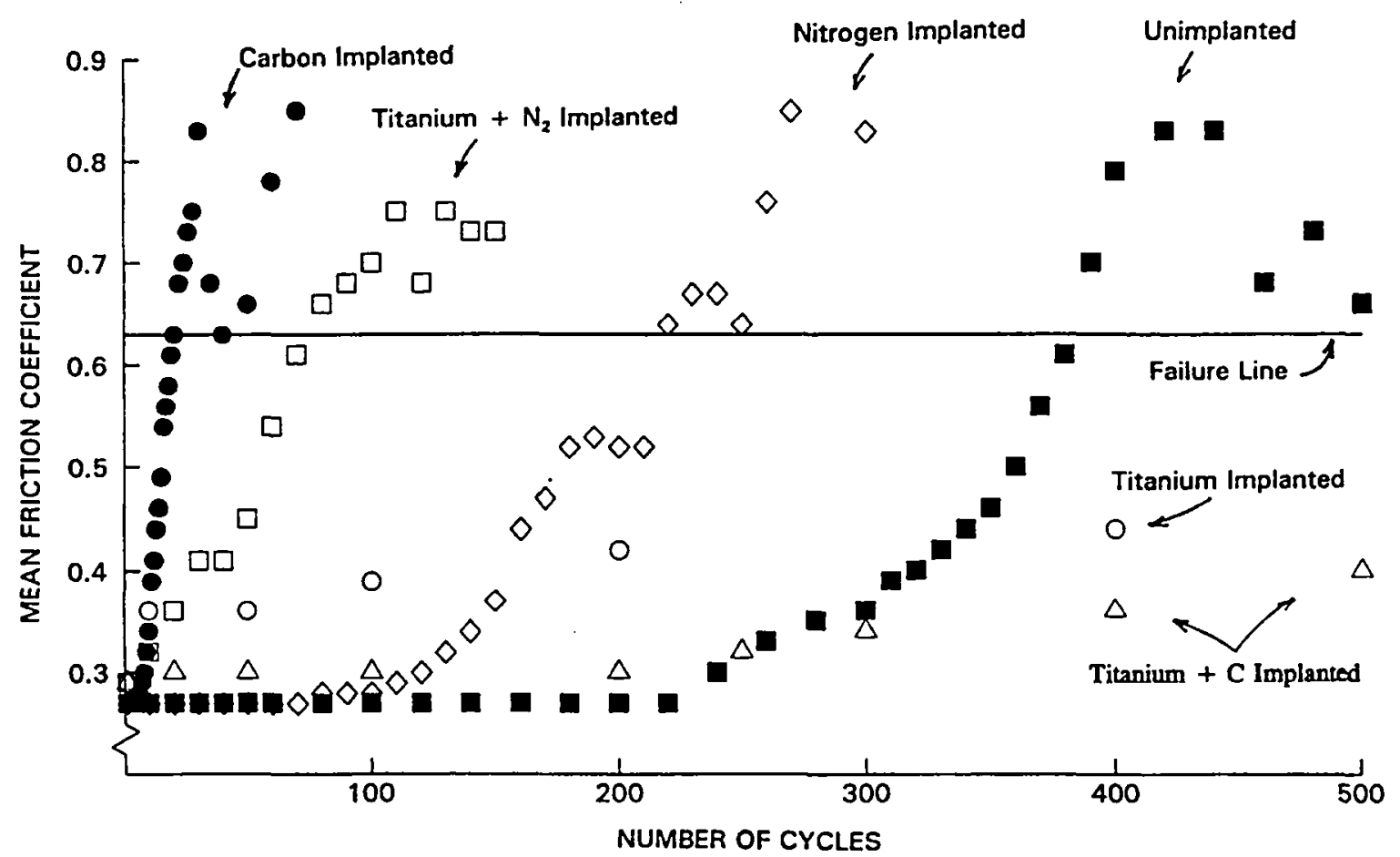

Figure 7. Typical Friction History Showing Effect of Ion Implantation Part b. Early History of Failure 


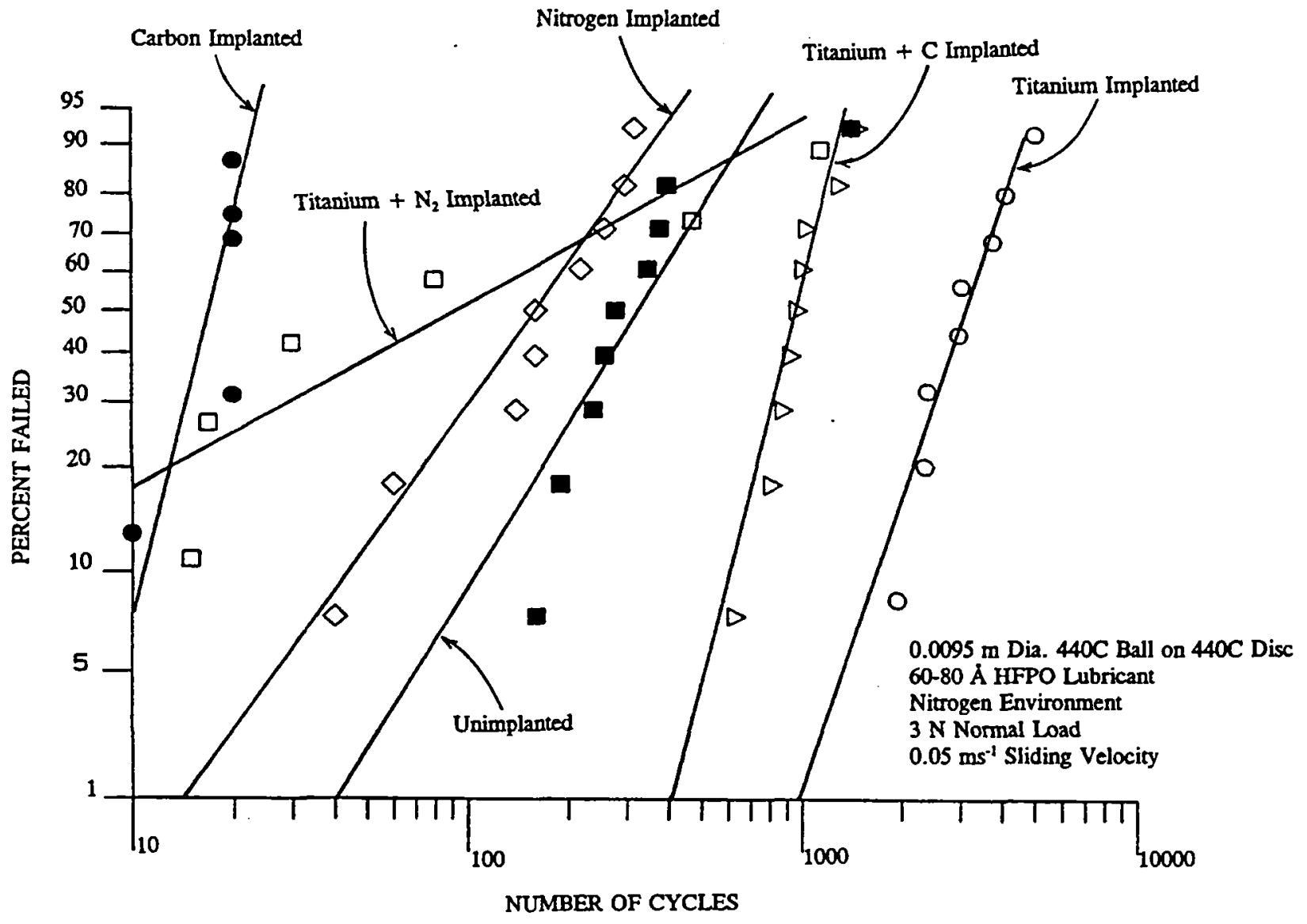

Figure 8. Effect of Ion Implantation on Weibull Distribution Lifetimes for Lubricated Dises. 


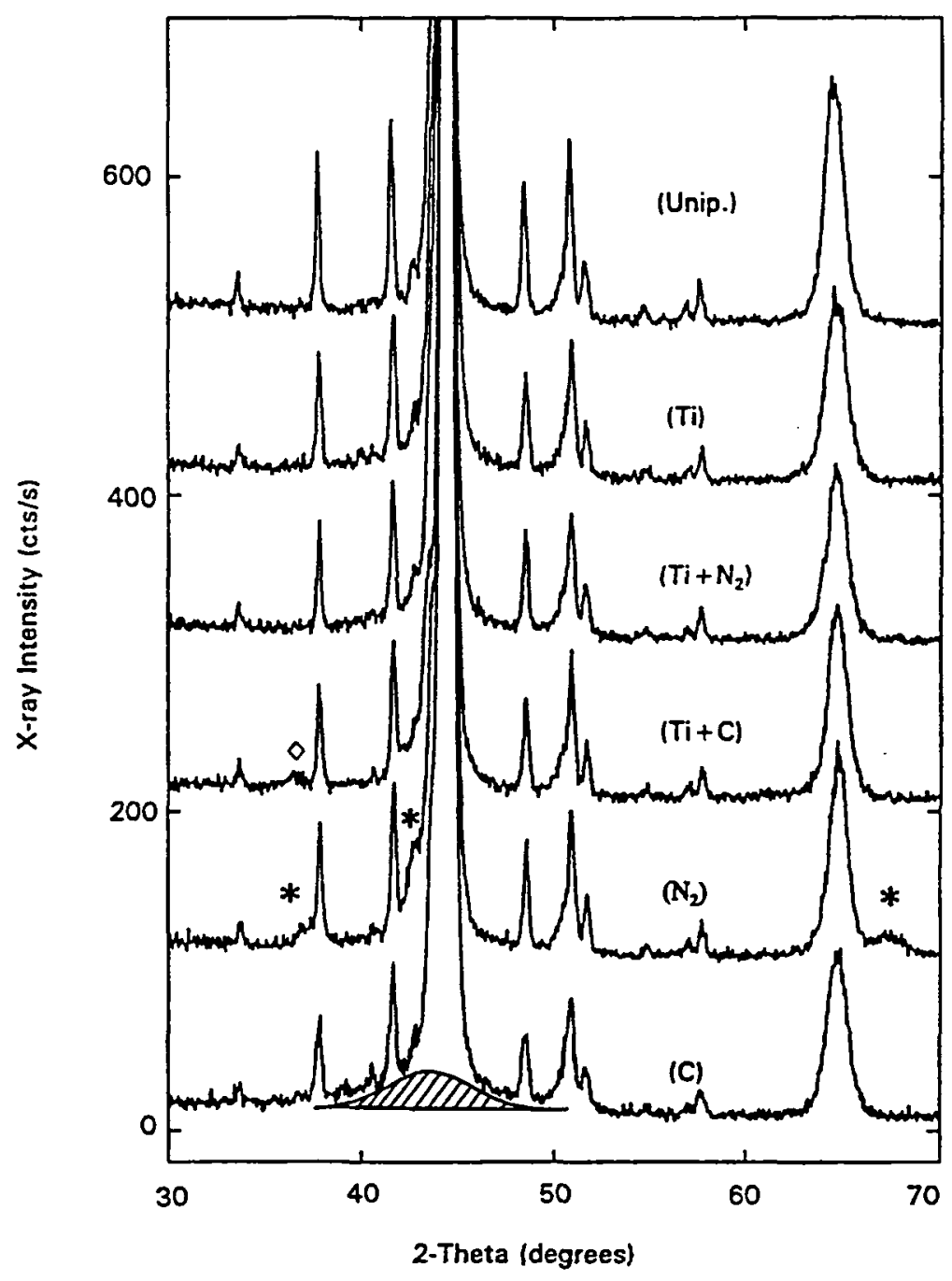

Figure 9.

Part a. Typical XRD Spectra for Unimplanted (Unip.) and Implanted Discs. $\left(\diamond-\mathrm{TiC}, *-\in(\mathrm{Fe}, \mathrm{Cr})_{2+\mathrm{x}} \mathrm{N}, \mathrm{ZZZ}\right.$ - amorphous $\left.\mathrm{Fe}-\mathrm{Cr}-\mathrm{C}\right)$. 


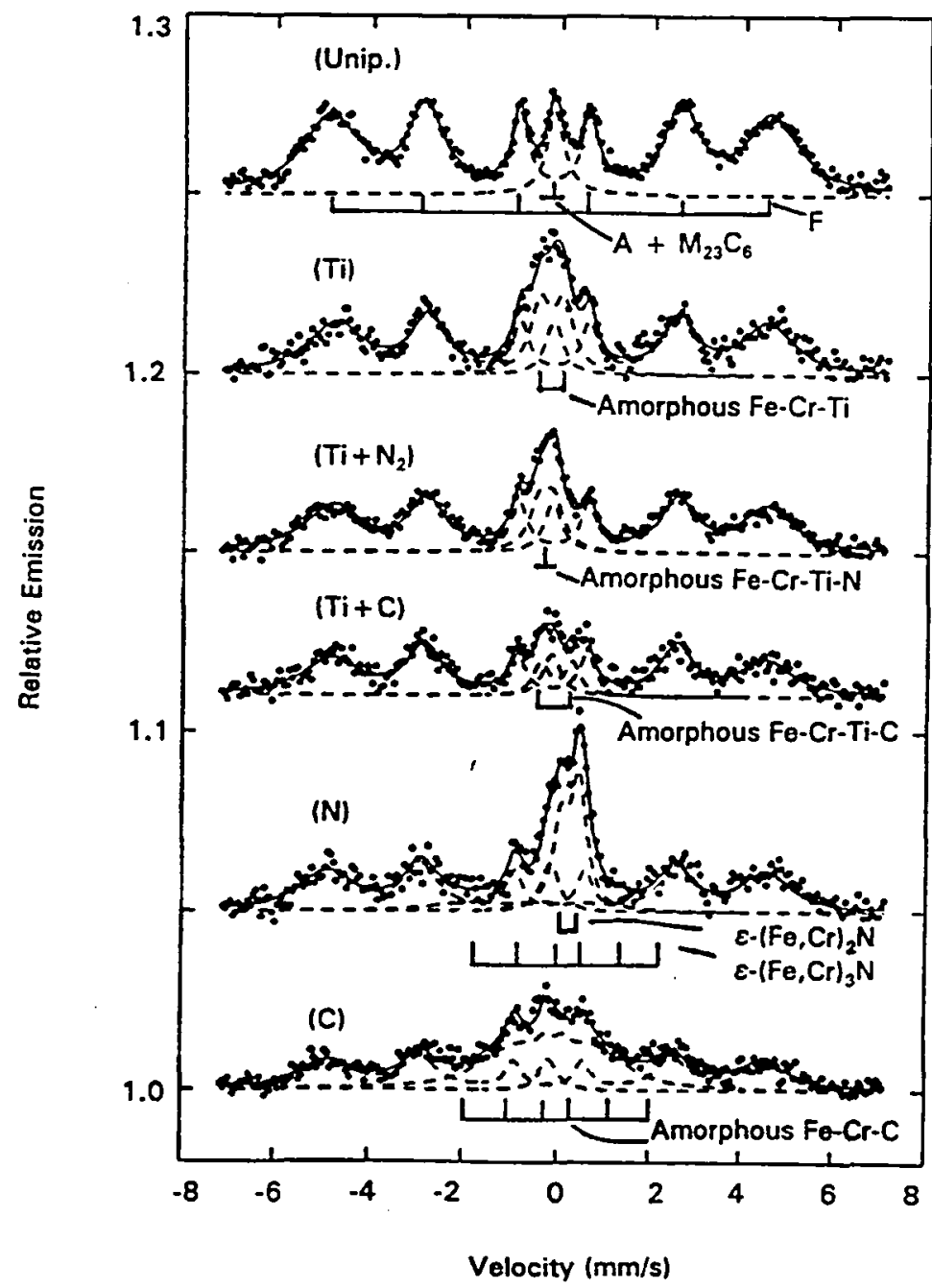

Figure 9.

Part b. Typical CEMS Spectra for Unimplanted (Unip.) and Implanted Discs. 



\begin{tabular}{|c|c|c|c|}
\hline \multicolumn{3}{|c|}{ REPORT DOCUMENTATION PAGE } & $\begin{array}{l}\text { Form Approved } \\
\text { OMB No. } 0704-0188\end{array}$ \\
\hline \multicolumn{4}{|c|}{ 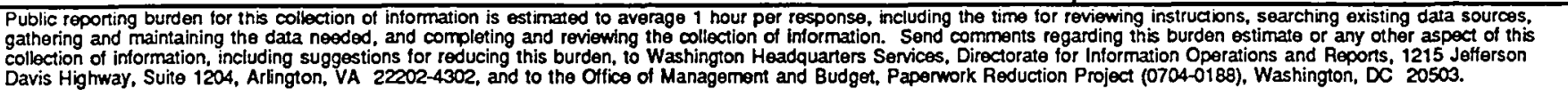 } \\
\hline 1. AGENCY USE ONLY (Leave blank) & $\begin{array}{r}\text { 2. REPORT DATE } \\
\text { August } 1995\end{array}$ & \multicolumn{2}{|c|}{ 3. REPORT TYPE AND DATES COVERED } \\
\hline \multicolumn{3}{|c|}{$\begin{array}{l}\text { 4. TITLE AND SUBTIILE } \\
\text { The Effects of Ion Implantation on the Tribology of Perfluoropolyether- } \\
\text { Lubricated } 440 \mathrm{C} \text { Stainless Steel Couples }\end{array}$} & 5. FUNDING NUMBERS \\
\hline \multicolumn{2}{|c|}{$\begin{array}{l}\text { Bradley Shogrin, William R. Jones, Jr., Paul J. Wilbur, Pilar Herrera-Fierro, } \\
\text { and Don L. Williamson }\end{array}$} & Herrera-Fierro, & WU-616-00-00 \\
\hline $\begin{array}{l}\text { 7. PERFORMING ORGANIZATION } \\
\text { National Aeronautics and } \\
\text { Lewis Research Center } \\
\text { Cleveland, Ohio } 44135 \text { - }\end{array}$ & $\begin{array}{l}\text { JAME(S) AND ADDRESS(ES) } \\
\text { pace Administration } \\
191\end{array}$ & $\begin{array}{l}\text { 8. } \mathbf{P E} \\
\mathrm{RI} \\
\mathrm{E}\end{array}$ & $\begin{array}{l}\text { ORMING ORGANIZATION } \\
721\end{array}$ \\
\hline \multicolumn{3}{|c|}{ 9. SPONSORING/MONITORING AGENCY NAME(S) AND ADDRESS(ES) } & NASA TM-106965 \\
\hline \multicolumn{4}{|c|}{$\begin{array}{l}\text { 11. SUPPLEMENTARY NOTES } \\
\text { Bradley Shogrin, Department of Mechanical Engineering, Colorado State University, Fort Collins, Colorado, presently at Case Western } \\
\text { Reserve University, Cleveland, Ohio 44106; William R. Jones, Jr., NASA Lewis Research Center; Paul J. Wibur, Department of } \\
\text { Mechanical Engineering, Colorado State University, Fort Collins, Colorado 80523; Pilar Herrera-Fierro, Ohio Aerospace Institute, } \\
\text { Cleveland, Ohio 44142; Don L. Williamson, Physics Department, Colorado School of Mines, Golden, Colorado } 80401 \text {. Responsible } \\
\text { person, William R. Jones, Jr., organization code 5140, (216) 433-6051. }\end{array}$} \\
\hline \multicolumn{3}{|c|}{$\begin{array}{l}\text { 12a. DISTRIBUTIONAVAILABILTY STATEMENT } \\
\text { Unclassified - Unlimited } \\
\text { Subject Category } 27 \\
\text { This publication is available from the NASA Center for Aerospace Information, (301) 621-0390. }\end{array}$} & TRIBUTKON CODE \\
\hline \multicolumn{4}{|c|}{$\begin{array}{l}\text { The lubricating lifetime of thin films of a perfluoropolyether (PFPE) based on hexafluoropropene oxide in the presence of ion } \\
\text { implanted } 440 \mathrm{C} \text { stainless steel is presented. Stainless steel discs, either unimplanted or implanted with } \mathrm{N}_{2}, \mathrm{C}, \mathrm{Ti}, \mathrm{Ti}+\mathrm{N}_{2} \text {, } \\
\text { or, } \mathrm{Ti}+\mathrm{C} \text { had a thin film of PFPE }(60-400 \AA \text { ) applied to them reproducibly }( \pm 20 \%) \text { and uniformly }( \pm 15 \%) \text { using a device de- } \\
\text { veloped for this study. The lifetimes of these films were quantified by measuring the number of sliding-wear cycles required } \\
\text { to induce an increase in the friction coefficient from an initial value characteristic of the lubricated wear couple to a final, or } \\
\text { failure value, characteristic of an unlubricated, unimplanted couple. The tests were performed in a dry nitrogen atmosphere } \\
(<1 \% \mathrm{RH}) \text { at room temperature using a } 3 \mathrm{~N} \text { normal load with a relative sliding speed of } 0.05 \mathrm{~ms}^{-1} \text {. The lubricated lifetime of } \\
\text { the } 440 \mathrm{C} \text { couple was increased by an order of magnitude by implanting the disc with Ti. Ranked from most to least effective, } \\
\text { the implanted species were: Ti; Ti }+\mathrm{C} \text {; unimplanted; } \mathrm{N}_{2} ; \mathrm{C} \simeq \mathrm{Ti}+\mathrm{N}_{2} \text {. The mechanism postulated to explain these results } \\
\text { involves the formation of a passivating or reactive layer which inhibits or facilitates the production of active cites. The cor- } \\
\text { responding surface microstructures induced by ion implantation, obtained using X-ray diffraction and conversion electron } \\
\text { Mössbauer spectroscopy, ranked from most to least effective in enhancing lubricant lifetime were: amorphous Fe-Cr-Ti; } \\
\text { amorphous Fe-Cr-Ti-C }+\mathrm{TiC} \text {; unimplanted; } \varepsilon-(\mathrm{Fe}, \mathrm{Cr})_{\mathrm{x}} \mathrm{N}, \mathrm{X}=2 \text { or } 3 \text {; amorphous Fe-Cr-C } \simeq \text { amorphous Fe-Cr-Ti-N. }\end{array}$} \\
\hline \multicolumn{3}{|l|}{ 14. SUBJECT TERMS } & $\begin{array}{l}\text { 15. NUMBER OF PAGES } \\
22\end{array}$ \\
\hline \multicolumn{2}{|c|}{ Perfluoropolyether; Boundary lubrication; Ion implantation } & & $\begin{array}{r}\text { 16. PRICE CODE } \\
\mathrm{A} 03\end{array}$ \\
\hline $\begin{array}{l}\text { 17. SECURTYY CLASSIFICATION } \\
\text { OF REPORT } \\
\text { Unclassified }\end{array}$ & $\begin{array}{l}\text { 18. SECURTY CLASSIFICATION } \\
\text { OF THIS PAGE } \\
\text { UnclasSified }\end{array}$ & $\begin{array}{l}\text { 19. SECURITY CLASSIFICATION } \\
\text { OF ABSTRACT } \\
\text { Unclassified }\end{array}$ & 20. LIMTAATION OF ABSTRACT \\
\hline NSN 7540-01-280-5500 & & & $\begin{array}{l}\text { ndard Form } 298 \text { (Rev. 2-89) } \\
\text { scribed by ANSI Std. Z39-18 } \\
-102\end{array}$ \\
\hline
\end{tabular}


- $\quad-$ 
National Aeronautics and

Space Administration

\section{Lewis Research Center}

21000 Brookpark Rd.

Cleveland, $\mathrm{OH}$ 44135-3191

Official Business

Penalty for Private Use $\$ 300$

POSTMASTER: If Undeliverable - Do Not Return 